\title{
Using an Acceptance and Commitment Therapy (ACT) Approach in Group Therapy to Alleviate Preoccupation with Body Weight in Universitas Indonesia Students
}

\author{
Rami Busyra Ikram ${ }^{\mathrm{a}}$, Ina Saraswati ${ }^{\mathrm{b} *}$, and Bona S.H. Hutahaean ${ }^{\mathrm{b}}$ \\ ${ }^{a}$ Faculty of Psychology, Universitas Indonesia, Depok, Indonesia; ${ }^{b}$ Department of Clinical \\ Psychology, Universitas Indonesia, Depok, Indonesia \\ * Corresponding author: \\ Ina Saraswati \\ Developmental Psychology Department \\ Faculty of Psychology, Universitas Indonesia \\ Jl. Lkr. Kampus Raya, Depok, Jawa Barat \\ Indonesia, 16424 \\ Tel.: +62 217270004 \\ Email address: ina.saraswati@ui.ac.id and ina.saraswati@gmail.com
}




\title{
Using an Acceptance and Commitment Therapy (ACT) Approach in Group Therapy to Alleviate Preoccupation with Body Weight in Universitas Indonesia Students
}

\begin{abstract}
Acceptance and Commitment Therapy (ACT) is a mindfulness-based therapy for increasing psychological flexibility. In this study, ACT helped individuals who evaluated themselves negatively with regard to their body weight. Specifically, this preliminary study aimed to alleviate students' preoccupation with being overweight through the application of a brief group ACT. Four students from Universitas Indonesia who experienced preoccupation with their body weight were provided with the ACTbased intervention once a week for three weeks. This study was conducted in a onegroup, before-after setting with non-random sampling. An MBSRQ-AS measurement was administered to all four students at pretest, post-test, and two-week follow-up. Our data showed that a reduction in their score on MBSRQ-AS measured from an average 3.63 at pretest to 2.63 at post-test, which it maintained at follow-up, at an average of 2.50. This result indicates an alleviation of preoccupation with body weight. Cohesiveness in the group was found to facilitate more openness and acceptance among the students during the group intervention; in addition, the group dynamics allowed the students to learn from each other's experiences. Therefore, preoccupation with body weight can be eased by the application of a brief ACT in a group setting. Future research is needed in the larger and wider population range, such as in middle and late adulthood.
\end{abstract}

Keywords: Acceptance and Commitment Therapy (ACT); college student; group therapy; preoccupation with body weight

\section{Introduction}

An individual's attention to their body image usually starts in adolescence or young adulthood. These developmental stages are marked by the occurrence of physical changes in both males and females. In females, the observable physical change involves breast growth and fat deposits in certain body parts that may affect the individual's evaluation of their body image (Papalia, Olds, $\&$ Feldman, 2009). Females pay more attention to their body image than males do (Algars et al, 2009). Physical changes in males tend to be seen as desirable, such as gaining more muscles, while physical changes in females tend to result in feelings of disappointment and anxiety because they often do not meet society's expectations for an ideal body (Algars et al, 2009).

Females' appraisal of their body weight is affected by multiple factors. One widely discussed factor is the thin-ideal internalization facilitated and encouraged by the mass media. Fashion magazines portray women with slim, tall bodies, which contribute to setting society's standards for an ideal female shape and size (Cash \& Pruzinsky, 2002; Field et al., 2001). Society's standards are easily internalized, making females believe that a bigger body size is unattractive. This thin-ideal internalization leads females to compare themselves to others and often results in feelings of dissatisfaction toward their own bodies (Wood \& Petrie, 2010; Ahern \& Hetherington, 2006; Bradford \& Petrie, 2008). 
Another factor that affects females' appraisal of their own body image is the cultural values adopted in certain regions (Fallom \& Jackson, as cited in Williams, 2004). There are several cultural values that emphasize a slimmer body as the most ideal body type (Bessenoff \& Snow, as cited in Algars et al., 2009). For example, in Javanese culture in Indonesia, slimmer women are perceived as more attractive because it is thought that they give more attention to taking care of their bodies (Suryaputri, 2011). Moreover, it is believed that the slimmer the body, the more attractive they are perceived to be by their peers (Wang, Houshyar, \& Prinstein, 2006). The desire to be accepted by society or one's peers may explain why females adopt society's and peers' body image ideals and then engage in certain behaviors such as dieting in their pursuit of acceptance.

A growing movement in society sees females with larger body sizes as incompetent in selfcontrol, as airheads, lazy, and less valuable; meanwhile, those with smaller body sizes are considered more successful, interesting, and able to take care of themselves well (Kring, Johnson, Davison, \& Neale, 2010). This stigma can cause larger bodied females to feel anxious, uncomfortable, rejected, and different from other people around them because they do not meet society's standards for thin-ideal body size. Society's standards can affect the way females appraise themselves. That is, it can make females feel that they are always fat even when their body mass index is within or even lower than the normal range. This negative appraisal of their body size makes females feel dissatisfied with their body weight and causes them to continually try to get thinner in pursuit of a body size that meets society's thin-ideal standards.

Body dissatisfaction is defined as a negative and subjective appraisal experienced by individuals with regard to their physical appearance. These include body weight and shape of abdomen and thigh, for example (Stice \& Shaw, 2002, as cited in Kring Johnson, Davison, \& Neale, 2010). Dissatisfaction with ones' body weight increases the risk of developing an eating disorder (Stice, 2001b). The more dissatisfied females feel about their body weight, the more effort they will put into exercise and strict dieting to attempt to achieve the ideal body size. Based on the DSM-IV TR (Diagnostic and Statistical Manual of Mental Disorders Fourth Edition-Text Revision, APA, 2000), a persistent preoccupation with body weight is one of the symptoms of an eating disorder. Common characteristics of eating disorders include intense fear of gaining weight and a disturbed perception of body shape and weight. This phenomenon corresponds with the study by Hrabosky, Masheb, White, and Grilo (2007), which showed that individuals' excessive negative evaluation of their body size positively correlated with the development of eating disorders.

Cognitive-Behavior Therapy (CBT) is the most commonly applied intervention in individuals with body image dissatisfaction. Mancuso (2016) explained that a lack of flexibility about body weight and shape can result in a negative evaluation of body image and maladaptive coping strategies. Individuals who are preoccupied with how overweight they are have difficulty accepting appraisal from others about their bodies. That exposition indicates that individuals who evaluate their body image negatively do so because of a lack of self-acceptance. The effectiveness of CBT comes from targeting individuals' negative evaluations of body image. However, this intervention was challenging to execute because altering individuals' irrational thoughts is not easy to accomplish (Vanderlinden, 2008). The technique of restructuring negative thoughts in CBT could backfire and develop into feelings of discomfort due a stronger belief in 
the negative evaluation of their own body size. Typically, individuals who increasingly strive to achieve thin-body size find it extremely difficult to stop the attendant behavior.

In order to help individuals who are preoccupied with being overweight, we conducted a brief ACT with a group of female students. The application of ACT in an effort to overcome body image issues has been done in various settings and populations, including female students (Pearson, Heffner, \& Follette, 2010). The advantage of the application of this intervention is that it can minimize the occurrence of eating disorders. This intervention utilizes mindfulness techniques to help individuals comprehend their personal experience without altering their thoughts (Herbert, Forman, \& England, 2009). In this intervention, we emphasized how females accept their body weight. One thing that requires special attention in an ACT is the balanced relationship between the therapist and the clients (Hayes, Pistorello, \& Levin, 2012). Clients are not perceived as individuals who got hurt or who are broken or hopeless. In addition, clients' painful experiences are accepted as a part of their lives. Moreover, the intervention does not try to erase painful experiences from their lives. Pearson, Heffner, and Follette (2010) developed ACT as a form of intervention to help individuals who experience dissatisfaction with their body image. They explain that ACT focuses on flexibility; therefore, it can facilitate the diversity of clients' needs.

Conducting the intervention program in a form of group therapy has a number of advantages. First, it is perceived to be effective in helping individuals with psychological issues because the group members are able to see and experience the growth and change happening for others. Group therapy can also increase individuals' capability of interacting socially among group members who experience the similar issues (Harcourt \& Rumsey, 2011). Participation in group intervention can also create a feeling of security and comfort. Group interventions encourage and facilitate members expressing themselves and their problems to others (Yalom \& Leszcz, 2005). Anxiety from not being accepted or being considered strange by others is often reduced because individuals realize that other people have the same problems or experiences as they do, and this is comforting. The existence of universality (feeling oneself as one with others) helps an individual realize they are not alone and they are safe. According to Yalom and Leszcz (2005), the process of emotional validation in the implementation of group intervention makes its members feel accepted instead of viewed negatively by others. Another benefit of group intervention is the opportunity to give and receive information within the construct of mutual support (Yalom \& Leszcz, 2005). Application of interventions in groups also facilitates individuals to provide benefits to others. In turn, the experience of providing help or support to others plays an important role in one's own therapeutic process because it can help heal the individual. According to Yalom and Leszcz (2005), the experience of helping others can foster a sense of worthiness and meaningfulness to others in the individual.

Considering that preoccupation with being overweight can lead to body dissatisfaction, and that individuals with negative body image tend to lack self-acceptance, it follows that ACT as a form of intervention can help individuals who experience body dissatisfaction issues. ACT may also help with body image issues. Our goal was to conduct a preliminary study to analyze the feasibility of applying this brief intervention to ease preoccupation with being overweight in adolescent and young adults. Our hypothesis is that preoccupation with being overweight can decrease following a brief group-based ACT. 


\section{Method}

\section{Participants}

Six participants (all females; mean age $=20.5$ years; average BMI score $=20.85$, i.e., $\mathrm{BMI}$ normal) were college students of Universitas Indonesia. According to the baseline data, they had an issue with their body image which was measured by the score of preoccupation with being overweight in the Multidimensional Body-Self Relations Questionnaire -Appearance Scale (MBSRQ-AS: Cash, 2000). Following a full explanation of the study procedures, we provided informed consent to participants. Participants were informed that they could withdraw from this study at any time. Initially, six participants experiencing the issue of being preoccupied with being overweight (Amelia, Baharnita, Elisa, Jeni, Kirana, and Malinda ${ }^{1}$ ) were recruited and consented to take part in the therapy. During the treatment, however, two participants (Jeni and Kirana) withdrew at the second session due to personal reasons related to their academic research schedules. The participants' demographic characteristics at the pretest are shown in Table 1.

Table 1.

Participants' Demographic Characteristics at Pretest

\begin{tabular}{lcccc}
\hline Name & Amelia & Baharnita & Elisa & Malinda \\
\hline Age & 19 & 20 & 20 & 20 \\
Weight $(\mathrm{kg})$ & 53 & 51 & 47 & 152 \\
Height $(\mathrm{cm})$ & 155 & 153 & 20,34 & 157 \\
BMI & 22,06 & 21,79 & thigh, cheek & $\begin{array}{c}\text { From the abdomen to the } \\
\text { bottom }\end{array}$ \\
$\begin{array}{l}\text { Body Area being concerned by } \\
\text { participants }\end{array}$ & $\begin{array}{c}\text { Cheek, abdomen, } \\
\text { thigh }\end{array}$ & Thigh & &
\end{tabular}

\section{Research Design}

This study used a one-group before-after study design with a non-random sampling method. As a preliminary study, we decided to focus on a group process in applying the brief ACT; therefore, there was no control group in this study. We conducted this intervention program with the goal of alleviating preoccupation with being overweight in a group of females. Intervention was performed by applying several ACT techniques. Participants' scores on the MBSRQ-AS were measured three times: at pretest, posttest, and follow-up. We did not use interviews as a method of participant assessment. However, the therapist provided several open-ended questions for participants to respond to in the form of a questionnaire. This method was employed to identify participants' perceptions of ideal body image, which body parts they disliked, and what external factors in affect participants' body dissatisfaction. Participants' answers were utilized as baseline data before conducting the intervention program.

\section{Measures}

The Multidimentional Body-Self Relations Questionnaire-Appearance Scale (MBSRQ-AS; Cash, 2000) is an instrument with four dimensions and a total of 34 items. However, body image was defined as an attitude toward physical appearance in this intervention (Cash, 2003; Cash,

\footnotetext{
${ }^{1}$ Those names are pseudonyms (not their real name)
} 
Morrow, Hrabosky, \& Perry, 2004); therefore, we did not use all of the items in the MBSRQ-AS. Interpretations of the MBSRQ-AS results were conducted based on certain subscales instead of on the overall scale; thus, only the relevant dimension was used.

The subscale used in this intervention was the preoccupation with being overweight due to a disturbed perception and excessive evaluation of body weight as precursors to the development of eating disorder symptoms. The overweight preoccupation dimension consisted of four items measured on a 5-point Likert scale. The MBSRQ-AS inventory was translated into Bahasa Indonesia and its psychometric properties were tested. The complete inventory was equally reliable as the overweight preoccupation dimension alone had a Cronbach alpha value of .82 (Christina, 2003). The scoring was done by summing up the score in each item of the overweight preoccupation dimension and dividing it by the total number of items in that dimension. Participants who scored above 2.67 were categorized as having preoccupation with being overweight.

\section{Procedure}

\section{Preparation Stage}

In the preparation stage, we conducted a screening process by administering a questionnaire which would provide the pretest data. Before conducting the intervention, we initiated a pilot study to gather baseline data. The online questionnaire was disseminated using Google Forms and consisting of a set of demographic questions and the MBSRQ-AS inventory.

After the baseline data was documented, we sorted the data by participants who were willing to receive a callback. The consideration for that assortment was to filter the participants so that the researcher could involve participants who truly needed and wanted to undergo this group-based ACT. Then, we called the participants who scored above 2.67 to take part in this intervention. We contacted the participant to confirm their consent for undergoing the intervention. The therapist gave participants the informed consent sheet, which stated that participants were willing to participate in the whole treatment voluntarily. Therefore, participants were aware of the benefits of this intervention. To respect the participants' privacy, we used pseudonyms as their identities.

\section{Intervention Stage}

The MBSRQ-AS inventory was administered in every session of the intervention to monitor the changes in preoccupation throughout the intervention. The program, which was adapted based on Pearson, Heffner, and Follette's design in 2010, were sessions with the topics "how long have you been struggling," "mindfulness of thought," and "the mindful mirror."

In the session "how long have you been struggling," participants were directed to visualize themselves as they began to realize discomfort to their body. Participants were asked to remember at what age they began to feel uncomfortable in their body; what clothes were they wearing at the time, what size were the clothes, and so on. The goal was to help participants become aware of the interrelationship of previous experiences that led to eventual feelings of discomfort with the body. 
Then, another technique that was also applied in the intervention sessions was "mindfulness of thought." This technique was used to examine the idea that thoughts are perceptions rather than actual facts. We also applied the mindfulness technique of "the mindful mirror." This exercise combined thoughts and emotions, and it facilitated the body's reception by experiencing and releasing difficult judgment and emotional thoughts (Pearson, Heffner, \& Follette, 2010). Looking in the mirror can be very difficult for many people, but it can be useful in letting participants know that they are not alone in this aspect of their struggle. The exercise was to just accept their own body and not compare it with other participants' bodies. In addition, the therapist also adapted the worksheet to identify values developed by Harris (2009). In participants" "value" activities, they are invited to do what is important in life so that they can reduce the things which interfere with their life goals.

ACT is an intervention that emphasizes flexibility and the individuals' needs, so there are no standards for frequency and duration of the treatment (Pearson, Heffner, \& Follette, 2010). They developed an ACT-based intervention which consisted of five sessions where each session lasts for one hour. For this study, we modified the intervention program into three sessions. The agendas for each session of interventions are shown in Table 2.

Table 2

Module for Each Session (Short Version)

\section{$\underline{\text { Session } 1}$}

Objective: Facilitate participants to focus more on values that are considered important in life and release negative mind hooks about the body image

\begin{tabular}{|c|c|}
\hline Activity & Evidence \\
\hline $\begin{array}{l}\text { Sharing their hopes and the } \\
\text { goals they want to achieve } \\
\text { by joining this intervention }\end{array}$ & $\begin{array}{l}\text { - Participants began to express their opinions more openly and share their experiences as related to } \\
\text { preoccupation with being overweight } \\
\text { - Want to know the judgment of others against self and to be more self-respecting }\end{array}$ \\
\hline $\begin{array}{l}\text { "How long have you been } \\
\text { struggling?" activity }\end{array}$ & $\begin{array}{l}\text { - The participants have a weight of } 50 \mathrm{~kg} \text {, so they feel different from their friends. } \\
\text { - Feeling very fat as a woman while the friends of guys on campus or at home have thinner and } \\
\text { proportionate bodies. } \\
\text { From this activity, realizing that feelings of discomfort have arisen since childhood. There was a } \\
\text { brother who said "you're fat." Then, friends on campus also say the same thing to this day. Not only } \\
\text { from friends, but social media also influences the beauty standards for one of the participants. This } \\
\text { motivates the participants to try to gain posture and body shape like the ideal women seen in social } \\
\text { media. }\end{array}$ \\
\hline Value & $\begin{array}{l}\text { - Participants realized a value that can make life more meaningful } \\
\text { - Participants argued that the values they uphold are a result of those embedded within their families } \\
\text { or through their observation of others }\end{array}$ \\
\hline
\end{tabular}


Table 2, cont.

Module for Each Session (Short Version)

\section{$\underline{\text { Session } 2}$}

Objective: Facilitate participants to receive negative thoughts / judgments about their bodies; define the mind against their bodies; to support each other and normalize their experience of dissatisfaction with their bodies

\begin{tabular}{|c|c|}
\hline Activity & Evidence \\
\hline Mindfulness of thought & $\begin{array}{l}\text { - Participants gain knowledge about mindfulness techniques that are useful for everyday life. The } \\
\text { technique teaches that thoughts you possess are only opinions and not facts that explain the real } \\
\text { situation. } \\
\text { Participants also know that it is important to live in "here and now" conditions and to realize that } \\
\text { thoughts, feelings, and experiences are part of an inseparable self. } \\
\text { - Some participants (Amelia and Baharnita) said they are still have many negative thoughts. However, } \\
\text { they began to sort out the main thoughts that often arose lately. In addition, one of the participants } \\
\text { suggested that she was not yet fully able to "distinguish" between mind and self. }\end{array}$ \\
\hline The mindful mirror & $\begin{array}{l}\text { - Participants know that mindfulness techniques can be applied to the body image problem } \\
\text { Participants also try to believe and apply the fact that that their thoughts that have occurred during } \\
\text { this time are not a reality } \\
\text { Participants (Amelia and Baharnita) argue that this mindful mirror technique actually makes them } \\
\text { compare themselves with others. } \\
\text { One of the participants (Malinda) also experienced obstacles focusing on the body image problem. } \\
\text { The thought that arises when she stands in front of the glass is related to something else; that is, her } \\
\text { anxiety about academics }\end{array}$ \\
\hline $\begin{array}{l}\text { Acceptance of unpleasant } \\
\text { experience }\end{array}$ & $\begin{array}{l}\text { - Participants recognize that having experiences that are considered less good by others is part of life } \\
\text { and not to think about it } \\
\text { Participants recognize that the most important thing in life is to be what you are and stay healthy } \\
\text { without hurting yourself } \\
\text { Participants know and realize the judgment of others will remain as hard as any self to look } \\
\text { beautiful and thin } \\
\text { Accepting the body condition as it is makes it look more attractive than trying to change according } \\
\text { to the appearance or judgment of others }\end{array}$ \\
\hline
\end{tabular}

\section{$\underline{\text { Session } 3}$}

Objective: Help participants find value in themselves; make "goals" or goals to be achieved and what things can be done to achieve her goal after being able to accept her body condition; make a commitment to the goals to be achieved

\begin{tabular}{l}
\hline \multicolumn{1}{c|}{ Ectivity } \\
$\begin{array}{l}\text { Life without body image } \\
\text { concern worksheet }\end{array}$ \\
- $\begin{array}{l}\text { Limited time makes the facilitator unable to ask each participant to propose a personal goal in the } \\
\text { future and a plan of concrete steps to take. } \\
\text { Participants who arrived late and did not attend the first session (Amelia), were asked to fill in the } \\
\text { "value" worksheet first. Later, she was asked to fill out this "life without body image concern" sheet } \\
\text { with reference to the "value" sheet. } \\
\text { There are two participants who talked about the purpose of life and the concrete steps that will be } \\
\text { followed to fit the personal values. } \\
\text { Participants (Baharnita) realize that the value of caring has been difficult to achieve so far because } \\
\text { she was too concerned about the appraisal by others. According to Baharnita, how can she shows } \\
\text { caring to others if she is not comfortable in the crowd and meeting with many people. }\end{array}$ \\
\end{tabular}

\section{Evaluation Stage}

An evaluation stage was conducted in order to study whether there was alleviation of preoccupation with being overweight in Universitas Indonesia students. The evaluation was conducted based on quantitative data analysis. 


\section{Data Analysis}

Data were analyzed using Friedman rank tests (for non-normal distribution variables) to assess change score of the MBSRQ-AS between before-after the intervention, then the score between before intervention and the follow-up score (two weeks after the termination of the last intervention). The purpose of the follow-up measurement was to evaluate the effect of the brief ACT-group after the session was completed. In addition, we used qualitative data by examining the observations and feedback from participants throughout the sessions.

\section{Results}

Although there were two participants (Jeni and Kirana) who withdrew at the beginning of the intervention due to academic scheduling reasons, the others attended all of the sessions. Four participants completed post-test, follow-up, and feedback forms. The flow diagram for the research process is shown in Figure 1.

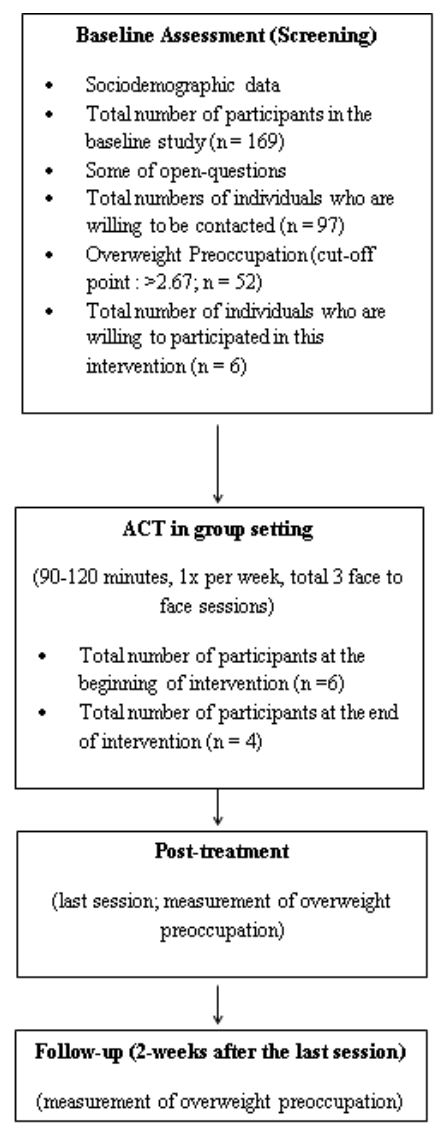

Figure 1. Flow Diagram of the research process

Generally, there were four participants whose overweight preoccupation scores decreased; i.e., Amelia, Baharnita, Elisa, and Malinda. Although there are participants who still scored above average compared to the overall sample, all participants showed a reduction in their follow-up 
test score compared to their pretest score. Figure 2 shows the reduction of the overweight preoccupation score in participants.

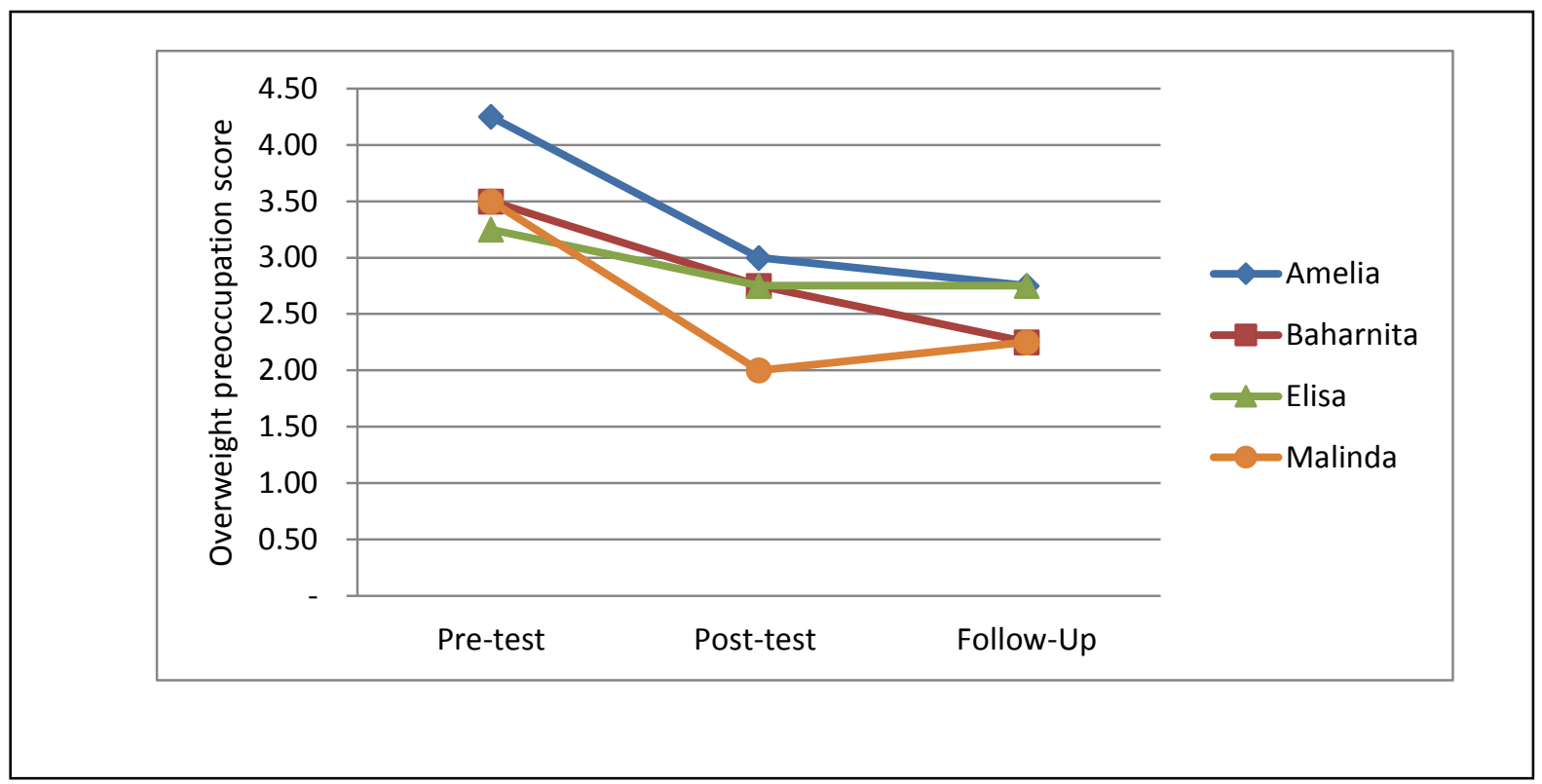

Figure 2. Overweight Preoccupation Score

According to statistical analysis, there was no difference in the mean score of overweight preoccupation between pre- and post-test. However, there were differences in mean score of overweight preoccupation between pretest and follow-up (Friedman; paired-comparisons; $p=$ .042; see Table 3). The mean scores at follow-up were lower than the pretest scores. These data indicate that brief group-based ACT could alleviate the overweight preoccupation at follow-up (two weeks after the termination of intervention).

Table 3

Means, standard deviation for overweight preoccupation outcome measures

\begin{tabular}{|c|c|c|c|c|c|c|}
\hline & & $p$-value & Mean & $S D$ & Minimum & Maximum \\
\hline Pretest & $\begin{array}{l}\text { Post-test } \\
\text { Follow-up }\end{array}$ & $\begin{array}{l}.066 \\
.042\end{array}$ & 3.6250 & .43301 & 3.25 & 4.25 \\
\hline Post-test & $\begin{array}{l}\text { Pretest } \\
\text { Follow-up }\end{array}$ & $\begin{array}{c}.066 \\
1.000\end{array}$ & 2.6250 & .43301 & 2.00 & 3.00 \\
\hline Follow-up & $\begin{array}{l}\text { Pretest } \\
\text { Post-test }\end{array}$ & $\begin{array}{c}.042 \\
1.000\end{array}$ & 2.5000 & .28868 & 2.25 & 2.75 \\
\hline
\end{tabular}

\section{Discussion}

The objective of this preliminary study was to analyze the feasibility of applying this brief intervention to attempt to ease preoccupation with being overweight in adolescents and young adults. It was hypothesized that overweight preoccupation could decrease through the application of brief ACT in a group. There was a significant change of score between the pretest and followup measurements. The results indicated that the excessive evaluation of body weight was in fact alleviated through the use of several techniques in a group setting. However, this study did not permit conclusions about the effectiveness of intervention. 
Body weight dissatisfaction indicates a distortion in the comprehension of one's body image. Initially, all of the participants in this intervention experienced cognitive distortion about their body weight, believing that they are fat. From previous research, it is known that even if they have a normal BMI, females usually still express certain dissatisfaction with their body weight (Algars et al., 2009; Hrabosky, Masheb, White, \& Grilo, 2007). Those findings correspond and are similar to the participants' narration in our intervention, where participants had a normal physical appearance but still believed that they are fat. Furthermore, their belief regarding their excessive body weight tended to focus on certain areas, such as the cheeks, belly, thighs and arms, even when they had a normal body weight according to the BMI identification session.

Factors that contributed to participants' appraisals of their body weight include family and peers. This corresponds with the literature study that claims that the negative appraisal of body image is affected by the society's judgment (family, peers, and social media) (Ahern \& Hetherington, 2006; Wang, Houshyat, \& Prinstein, 2006). Society's judgment is then internalized into one's personal values, making them see bigger bodies as unattractive. This condition perpetuates the feeling of possessing excessive body fat and also their attempt to reduce it.

In Baharnita's case, she had experienced dissatisfaction with her body weight since she started her first year of college. In her judgment, most of her female friends were slim and thin. Baharnita also felt that her body was bigger than her male friends on campus. Judgment also came from her boyfriend, who told her that she is fat; this also affected her confidence about her body weight and her appearance. On top of that, social media also played a role that affected Baharnita's perception toward her body weight. This narrative comes from Baharnita's exposition, where she explained that she felt she did not fit into the beauty standard which was developed on social media platforms. She felt that females should possess a smaller posture and size than their male counterparts. This explanation indicates that peers' body weight and appearance are acting as the ideal standard for Baharnita. Her appraisal of not possessing the ideal standard of body weight and appearance perpetuated her anxiety and made Baharnita uncomfortable interacting with people. She will be is anxious about being negatively appraised by people from her social circle. In another case, Elisa's dissatisfaction toward her body weight is also affected by people in her social circle. Even though Elisa's parents perceived her body as ideal, Elisa is still anxious about gaining weight. In this case, peers can be considered the stronger contributing factor toward her perception of body weight.

Based on the ACT techniques, we know that mindfulness of thought and the mindful mirror can stimulate participants to come up with their own insights as to where their negative thoughts are perceived as mere opinion and not resembling reality (Pearson, Heffner, \& Follette, 2010). In mindfulness activities, participants also stated that they could not fully accept themselves. They also felt unable to fully eliminate negative thinking. Participants realized that people's judgment of their appearance or body weight will always be there in any situation; therefore, overthinking on this issue is unnecessary. They understand that accepting their current body weight or shape will create a better image and will encourage feelings of comfort with one's self. In this case, it is found that ACT-based therapy is not trying to eradicate or alter participants' unpleasant experience, but rather on focusing on learning how to accept those experiences and thoughts as part of one's self. Through "how long have you been struggling" activities, participants became aware that negative experiences with family and friends have been around for a long time. 
Through ACT-based group intervention, participants also understood that they did not have excessive body weight, but that in fact they fall into the "normal" category of body weight. On top of that, participants also realized that their negative thoughts about body image are not facts; they are just negative thoughts that come out of fear. Consequently, participants also learned to accept themselves. Therefore, the preoccupation with body weight could be alleviated as manifested in their score on the overweight preoccupation subscales before and after the intervention took place. By recognizing the negative experiences, thoughts, and emotions they had toward body weight and appearance, participants were more able to accept themselves as they are. This helped the participants see that they could plan life goals that correspond to their values. Negative preoccupation toward body weight was capable of dragging them away from their values or even their life goals.

Based on our observation of the group dynamic and the feedback from the participants, our findings are that the ACT-based group intervention can induce positive developments in the perception of body image, especially for body weight. The learning process in the group helped participants learn how to accept their own problems. Seeing similarities in other individuals within the group helped participants feel accepted by others so that they became more open to expressing their feelings. The group environment normalized the experience for participants, allowing them to feel comfortable. They also found satisfaction in being members of the group. Applying the short ACT in a group setting exerted a stronger influence on activity around discussing weight issues. Although there were two people who quit by the second session, it did not interfere with the rest of the group's progress. Participants admitted that they enjoyed the benefits of participating in the intervention sessions.

Cohesiveness within the group helped each participant face their problems. Facing a collective goal facilitated the individual's openness when interacting and sharing, and allowed the individual to be more accepting (Harcourt \& Rumsey, 2011). One of the participants stated that this intervention helped her gain numerous insights and altered her negative thoughts. Participants also reported that negative appraisal by others also served as a key role in better understanding themselves. This understanding helped the participants become more selfaccepting while participating in this intervention.

This intervention can be considered an effective and feasible method that can be applied to adolescents and young adults. Participants learned about the content from each session, but they also learned about other factors that affect their self-development. Participants understood that the way the therapist delivered the material could be one of the factors that contributed to feeling comfortable during the intervention. They felt accepted and not judged by the therapist because they of their negative thoughts about their own body image. Painful experiences were accepted as part of their lives and they were encouraged not to repress their memories. This corresponds with the exposition stated by Hayes, Pistorello, and Levin (2012), where the professional relationship between therapist and participant is important and the therapist is encouraged not to try to force the participant to change.

We noted some limitations of this study, including the lack of assessment in the form of in-depth interviews before and after the sessions took place. In-depth interviews before and after the intervention would serve the purpose of identifying how much each session benefited each 
participant. In addition, if there were male participants, we believe that would provide a more comprehensive description of overweight preoccupation in both sexes.

We cannot determine the long-term effect of this intervention to reduce preoccupation with being overweight. This is because the follow-up measurement occurred only two weeks after termination. Behavioral change might be hard to achieve in such a short period of time. For further research, we suggest involving a control group so as to understand the extent to which ACT group implementation is effective in reducing preoccupation with being overweight. We also suggest investigating the population of individuals diagnosed with eating disorders, such as anorexia or bulimia.

\section{References}

Ahern, A. L., \& Hetherington, M. M. (2006). The thin ideal and body image: an experimental study of implicit attitudes. Psychology of Addictive Behaviors, 20(3), 338-342.

Algars, M., Santtila, P., Varjonen, M., Witting, K., Johansson, A., Jern, P., \& Sandnabba, N. K. (2009). The adult body: how age, gender, and body mass index are related to body image. Journal of Aging and Health, 21(8), 1112-1132.

Bradford, J. W., \& Petrie, T. A. (2008). Sociocultural factors and the development of disordered eating: a longitudinal analysis of competing hypotheses. Journal of Counseling Psychology, 55(2), 246-262.

Cash, T. F. (2000). The multidimensional body-self relation questionnaire: MBSRQ user's manual (3 ${ }^{\text {rd }}$ Rev.ed.). Virginia: Old Dominion.

Cash, T. F., \& Pruzinsky, Y. (2002). Body image: a handbook of theory, research, and clinical practice. New York: Guilford Press.

Cash, T. F. (2003). Body image: Past, present, and future. Body Image: An International Journal of Research, 1, 1-5.

Cash, T. F., Morrow, J. A., Hrabosky, J. I., \& Perry, A. A. (2004). How has body image changed? A cross-Sectional investigation of college women and men from 1983 to 2001. Journal of Counseling and Clinical Psychology, 72(6), 1081-1089.

Christina, D. (2003). Gambaran Citra Tubuh pada Wanita yang Mengalami Obesitas dan Penelaahan MBSRQ-AS (Master's Thesis). Universitas Indonesia, Depok.

Field, A. E., Camargo, C. A., Taylor, B., Berkey, C. S., Roberts, S. B., \& Colditz, G. A. (2001). Peer, parent, and media influence on the development of weight concerns and frequent dieting among preadolescent and adolescent girls and boys. Pediatrics, 107, (1), 54-60.

Harcourt, D., \& Rumsey, N. (2011). Body image and biomedical interventions for disfiguring conditions. In T. F. Cash \& L. Smolak (Ed.), Body image: a handbook of science, practice, and prevention (pp. 404 - 414). New York: Guilford.

Harris, R. (2009). ACT Made Simple. Oakland: New Harbinger Publications.

Hayes, S. C., Pistorello, J., Levin, M.E. (2012). Acceptance and commitment therapy as an unified model of behavior change. The Counseling Psychologist, 40 (7) 976-1002.

Herbert, J. D., Forman, E. M., \& England, E. L. (2009). Psychological Acceptance. In W. O’Donohue \& J. E. Fiseher (Ed.), General principles and empirically supported techniques of cognitive behavior therapy (pp. 102-114). Hoboken: John Wiley.

Hrabosky, J. I., Masheb, R. M. White, M. A., \& Grilo, C. M. (2007). Overevaluation of shape and weight in binge eating disorder. Journal of Consulting and Clinical Psychology, 75(1), 175-180.

Kring, A. M., Johnson, S. L., Davison, G. C., \& Neale, J. M. (2010). Abnormal Psychology (12 ${ }^{\text {th }}$ ed.). UK: John Wiley \& Sons.

Mancuso, S. G. (2016). Body image inflexibility mediates the relationship between body image evaluation and maladaptive body image coping strategies. Body Image, 16, 28-31.

Papalia, D. E., Olds, S. W., \& Feldman, R. D. (2009). Human Development (11 ${ }^{\text {th }}$ ed.). New York: McGraw Hill.

Pearson, A. N., Heffner, M., \& Follette, V. M. (2010). Acceptance \& commitment therapy for body image dissatisfaction. USA: New Harbinger Publications.

Suryaputri, I. Y. (2011). Pengaruh citra tubuh terhadap kepuasan perkawinan yang dimediasi oleh frekuensi hubungan seksual dan kepuasan seksual (pada wanita dan pria dewasa muda di Indonesia) (Master's Thesis). Universitas Indonesia, Depok.

Vanderlinden, J. (2008). Many roads lead to Rome: Why does cognitive behavioural therapy remain unsuccessful for many eating disorder patients? European Eating Disorders Review, 16(5), 329-333

Wang, S. S., Houshyar, S., \& Prinstein, M. J. (2006). Adolescent girls' and boys' weight-related health behaviors and cognitions: associations with reputation and preference-based peer status. Health Psychology, 25(5), 658-663.

Williams, E. F. (2004). The body image quality of life inventory: further validation with college men and women. Body Image: An International Journal of Research, 1, 279-287. 
Wood, N. A. R., \& Petrie, T. A. (2010). Body dissatisfaction, ethnic identity, and disordered eating among African American women. Journal of Counseling Psychology, 57(2), 141-153.

Yalom, I. D., \& Leszcz, M. (2005). The Theory and Practice of Group Psychotherapy (5 ${ }^{\text {th }}$ ed.). New York: Basic Books. 